\title{
Effect of Water Content on the Morphology of ZnO Powders Synthesized in Binary Solvent Mixtures by Glycol Process
}

\author{
Kongsy Phimmavong, Jeong-Hwan Song*,', Seung-Beom Cho**, and Dae-Young Lim** \\ Department of Materials Engineering, Graduate School of PaiChai University, Daejeon 35345, Korea \\ *Department of Materials Science and Engineering, PaiChai University, Daejeon 35345, Korea \\ **Information Technology \& Electronic Materials, LG Chem. Research Park, Daejeon 34122, Korea
}

(Received March 10, 2017; Revised April 6, April 25, 2017; Accepted April 25, 2017)

\begin{abstract}
$\mathrm{ZnO}$ nanopowder was synthesized using a relatively facile and convenient glycol process. $\mathrm{ZnO}$ nanopowder was successfully synthesized at temperatures as low as $125^{\circ} \mathrm{C}$ using zinc acetate as the $\mathrm{Zn}$ source and 1,4-butanediol as the solvent. Then, the effects of water content on the growth process and morphological evolution of $\mathrm{ZnO}$ powders were investigated using 1,4-butanediol and water as binary solvent mixtures. Using pure 1,4-butanediol at a temperature above $125^{\circ} \mathrm{C}$, the prepared hexagonal $\mathrm{ZnO}$ nanopowder exhibited a quasi-spherical shape with average crystalline size of approximately $30-50 \mathrm{~nm}$. It is also demonstrated that the morphology of $\mathrm{ZnO}$ powders can be controlled by the addition of various water content in 1,4-butanediol. With increasing water content, the morphologies of the $\mathrm{ZnO}$ powders changed sequentially from quasi-spherical to hexagonal plate and pyramid, and finally to hexagonal prismatic with a pyramidal tip. A sharp peak centered at $384 \mathrm{~nm}$ in the UV region and a weak broad peak in the visible region between 450 and $700 \mathrm{~nm}$ were shown in the room temperature PL spectra of the $\mathrm{ZnO}$ synthesized using the glycol process, regardless of the addition of water, suggesting that $\mathrm{ZnO}$ nanopowders with the best crystallinity were obtained under these conditions.
\end{abstract}

Key words : ZnO, Glycol process, Binary solvent, Morphology

\section{Introduction}

$\mathrm{Z}$ $\mathrm{nO}$, which is a II-VI binary compound semiconductor, resides at the borderline between the covalent and ionic semiconductors. The crystal structure of $\mathrm{ZnO}$ exhibits the polymorphism of thermodynamically stable hexagonal wurtzite and metastable cubic (zinc blende and rocksalt) phases. $\mathrm{ZnO}$ crystallizes in either a cubic zinc blende or a hexagonal wurtzite structure in which each anion of oxygen is surrounded by four cations of zinc at the corners of a tetrahedron, and vice versa.

$\mathrm{ZnO}$ can be found in numerous industrial products such as ceramics, catalysts, rubber additives, paints, medical, cosmetics, etc. ${ }^{1)}$ Also, it is used in solar cell windows, piezoelectric transducers, gas sensors, ultraviolet (UV) light emitting/detecting technology and devices with optoelectronic properties. ${ }^{2-6)}$ It has many advanced properties, such as wide band gap energy (3.37 eV) with large exciton binding energy (60 meV), high transparency, very low resistivity with superior electron transport, nontoxicity and abundance in nature.

\footnotetext{
${ }^{\dagger}$ Corresponding author : Jeong-Hwan Song

E-mail : song_jeonghwan@pcu.ac.kr

Tel : +82-42-520-5916 Fax : +82-70-4850-8458

*Corresponding author : Dae-Young Lim

E-mail : dylim@pcu.ac.kr

Tel : +82-42-520-5392 Fax : +82-70-4850-8458
}

Recently, the properties of $\mathrm{ZnO}$ have been found to depend on its underlying structure, which is considerably dependent on the crystal size and morphology. Various methods have been attempted for the preparation of $\mathrm{ZnO}$ crystallites, including the sol-gel method, thermal evaporative decomposition of solutions, wet chemical synthesis, chemical vapor deposition and the hydrothermal method. ${ }^{7-10)}$ However, most of these methods involve high temperatures, high cost and sometimes complicated processes, which might result in impurities in the final products.

In order to obtain $\mathrm{ZnO}$ with appropriate chemical and optoelectronic properties for intended applications, control of morphology and particle size are very important. Especially, numerous studies have demonstrated that different morphologies of $\mathrm{ZnO}$ such as spherical, rod-like, flower-like, tube, disk and wires can be successfully synthesized by various methods. ${ }^{9-16)}$

The glycol for the glycol process has multiple functions: it acts as a nonaqueous solvent, stabilizer, and reducing agent; limits particle growth; and prevents agglomeration. The glycol process have proven to be useful in the synthesis of metal sulfide and oxide nanopowders because of their relatively facile and convenient procedures and low reaction temperatures without the need of a mineralizer for processing. In this paper, we present a glycol process to synthesize highly crystallized $\mathrm{ZnO}$ nanopowders at low reaction temperature. The effect of a binary solvent of 1,4-butanediol and water on the morphology of $\mathrm{ZnO}$ synthesized by glycol 
process is described, and its properties are characterized.

\section{Experimental Procedure}

The $\mathrm{ZnO}$ nanopowders were synthesized using a glycol process in a glycol solvent. In this study, zinc acetate dihydrate $\left(\mathrm{Zn}\left(\mathrm{CH}_{3} \mathrm{COO}\right)_{2} \cdot 2 \mathrm{H}_{2} \mathrm{O}\right)$ and 1,4-butanediol $\left(\mathrm{C}_{4} \mathrm{H}_{10} \mathrm{O}_{2}\right)$ were used as $\mathrm{Zn}$ source material and nonaqueous solvent. Various water contents were used as a part of the binary solvent mixtures to control the morphology of the $\mathrm{ZnO}$ powders obtained. First, $0.05 \mathrm{~mol}$ of zinc acetate dihydrate was dissolved in $100 \mathrm{ml}$ of 1,4-butanediol and in binary solvent mixtures of $100 \mathrm{ml}$ of 1,4-butanediol and various contents of water. The resulting solutions were transferred to a $1000 \mathrm{ml}$ 3 neck-glass container with heating mantle. To investigate the effect of the different synthesis conditions on the phase and morphology of the obtained powders, the glycol reactions were performed at temperatures ranging from 100 to $175^{\circ} \mathrm{C}$ for $30 \mathrm{~min}$. The content of water at the desired temperature and time was varied between 0 and $30 \mathrm{ml}$. After the glycol reaction, the glass container was cooled to room temperature. The obtained powders were washed at least 3 times by repeated cycles of centrifugation and redispersion in ethanol and dried at $100^{\circ} \mathrm{C}$ in a dry oven for $24 \mathrm{~h}$.

The dried powders were analyzed using X-ray diffraction (XRD-D1w, Target: Cu, $30 \mathrm{kV}-30 \mathrm{~mA}$, Shimazu, Japan) over a $2 \theta$ range of 10 to $80^{\circ}$ with a scanning speed of $2 \% \mathrm{~min}$ to determine the phase composition and crystal structure. The morphology of the synthesized powders was observed using field emission scanning electron microscopy (FESEM, S-4800, Hitachi, Japan) and transmission electron microscopy (TEM, JEM-2100F, JEOL, Japan). The diffuse reflectance spectroscopy (DRS) and photoluminescence (PL) of the $\mathrm{ZnO}$ powders were analyzed using a ultraviolet-visible (UV-Vis) spectrometer (JASCO V550, Japan) with $\mathrm{BaSO}_{4}$ as a reference standard and a He-Cd laser with a wavelength of $325 \mathrm{~nm}$ as an excitation source at room temperature (LabRAM, Horiba).

\section{Results and Discussion}

The XRD patterns of each powder obtained by the glycol process at various reaction temperatures for the same reaction time of $30 \mathrm{~min}$ are shown in Fig. 1. At the reaction temperature of $100^{\circ} \mathrm{C}$, the XRD pattern of the powder shows the peak of crystalline $\mathrm{ZnO}$ as the main hexagonal phase and that of poorly crystalline Zn-glycolate as a second phase. Pure $\mathrm{ZnO}$ powders of hexagonal structure were prepared without any second phases at temperatures of $125^{\circ} \mathrm{C}$ and over, and the entire set of peak patterns matches the reference peaks reported on JCPDS Card No. 89-0510. Upon increasing the reaction temperature, the diffraction peaks of $\mathrm{ZnO}$ became more intense and narrow, reflecting an increase in the crystallinity of the hexagonal phase. The crystallite size of the $\mathrm{ZnO}$ powder was calculated from the broadening of the (101) peak using Scherrer's equation:

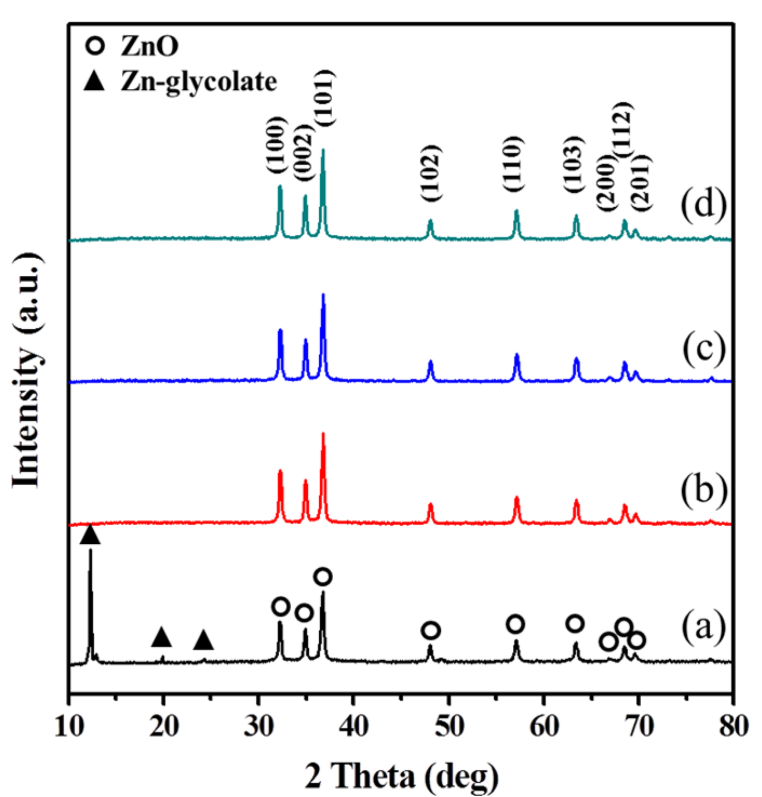

Fig. 1. XRD patterns of $\mathrm{ZnO}$ powder obtained by glycol process at various reaction temperatures for $30 \mathrm{~min}$ : (a) $100^{\circ} \mathrm{C}$, (b) $125^{\circ} \mathrm{C}$, (c) $150^{\circ} \mathrm{C}$, and (d) $175^{\circ} \mathrm{C}$.

$$
D=\frac{0.89 \lambda}{\beta \cos \theta}
$$

where $D$ is the average crystalline size, $\lambda(=0.15406 \mathrm{~nm})$ is the wavelength of $\mathrm{Cu}, \beta$ is the full-width at half-maximum, and $\theta$ is the diffraction angle of the center of the peak. The crystalline size of the synthesized $\mathrm{ZnO}$ nanopowder was observed to be approximately $30-40 \mathrm{~nm}$.

FE-SEM images of each powder synthesized at various reaction temperatures for $30 \mathrm{~min}$ using the glycol process are presented in Fig. 2. The $\mathrm{ZnO}$ powder obtained at the relatively low reaction temperature of $125^{\circ} \mathrm{C}$ consisted of aggregated secondary powders with spherical morphology and a size of approximately $300-500 \mathrm{~nm}$; these powders contained many small primary nanopowders with size of approximately $20 \mathrm{~nm}$, as shown in Fig. 2(a). The SEM images reveal that the size of the $\mathrm{ZnO}$ nanopowders increased from 30 to $50 \mathrm{~nm}$ when the reaction temperature was increased from 150 to $175^{\circ} \mathrm{C}$, as can be observed in Figs. 2(b) and (c). Furthermore, the obtained $\mathrm{ZnO}$ nanopowders also exhibited a quasi-spherical morphology without aggregation or morphological change. We suggest that the formation of the aggregate as a spherical powder is the result of the dipole nature of $\mathrm{ZnO}$ on the nanometer scale at lower reaction temperatures, as shown in Fig. 2(a). However the aggregation of nanocrystallites decreases with an increase in the temperature because of the flammability and decomposition of 1,4-butanediol at or above the flash point of approximately $134^{\circ} \mathrm{C}$.

Figure 3 presents a TEM image and corresponding selected-area electron diffraction (SAED) pattern of the $\mathrm{ZnO}$ nanopowder synthesized by the glycol process at $150^{\circ} \mathrm{C}$ for $30 \mathrm{~min}$. The $\mathrm{ZnO}$ nanopowders, with quasi-spherical shape, 

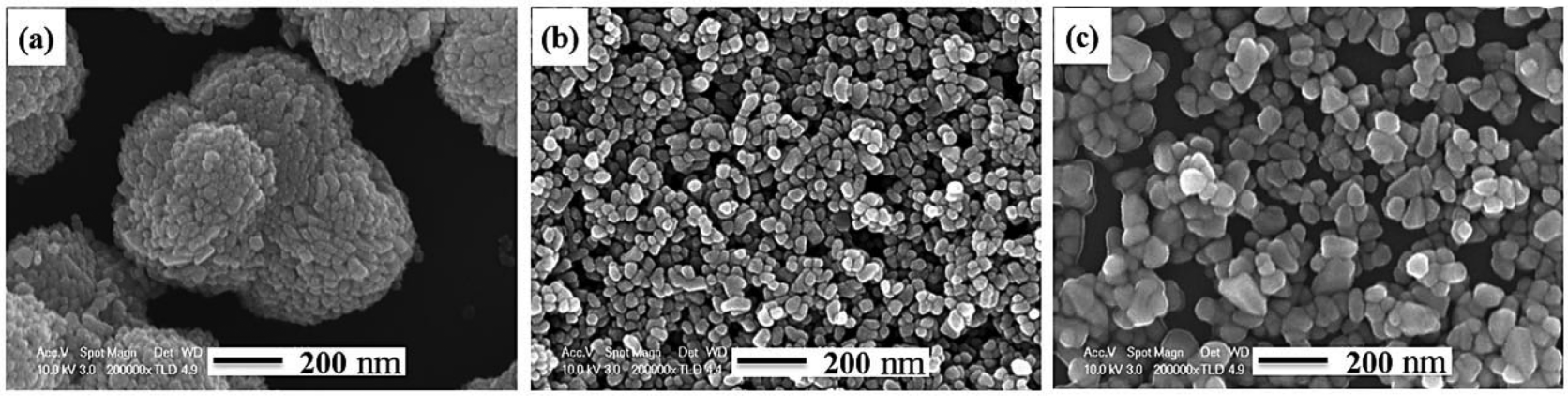

Fig. 2. FE-SEM images of $\mathrm{ZnO}$ powder obtained by glycol process at various reaction temperatures for 30 min: (a) $125^{\circ} \mathrm{C}$, (b) $150^{\circ} \mathrm{C}$, and (c) $175^{\circ} \mathrm{C}$.
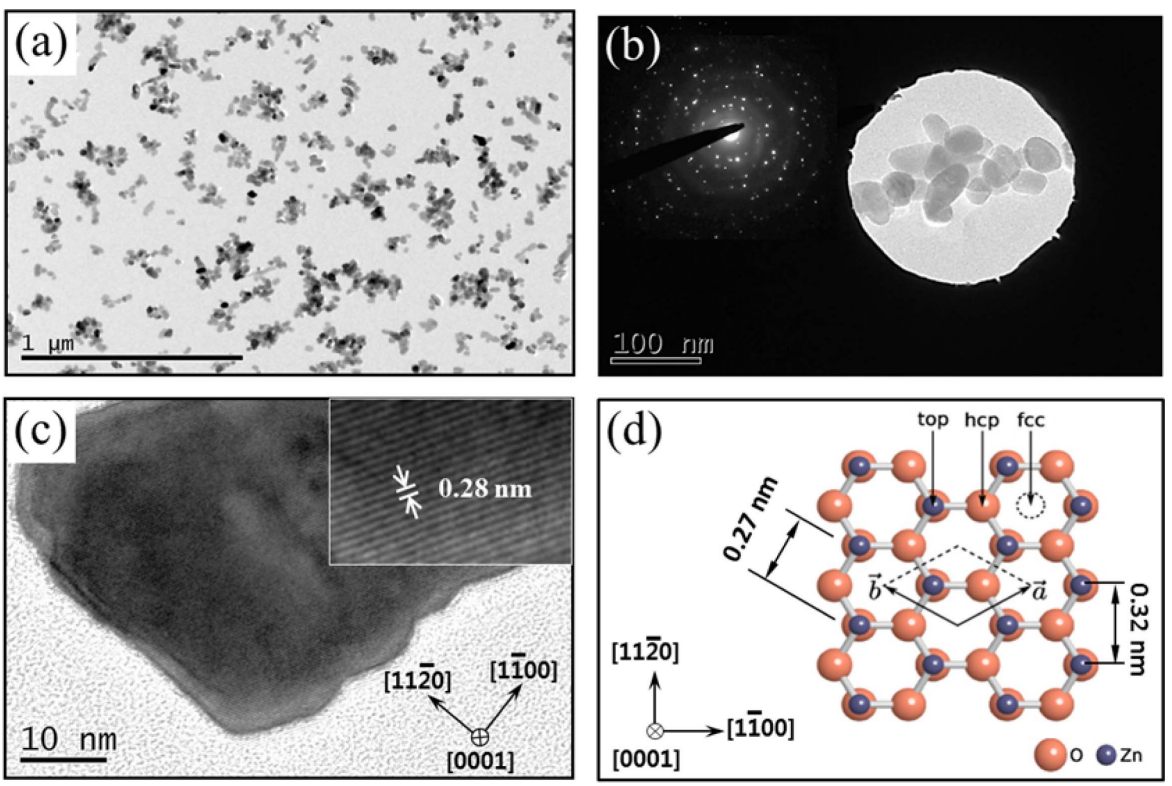

Fig. 3. (a) TEM image of $\mathrm{ZnO}$ nanopowder obtained by glycol process at $150^{\circ} \mathrm{C}$ for $30 \mathrm{~min}$, (b) SAED pattern, (c) HRTEM image, and (d) schematic illustration of top view of wurtzite structure and atom configuration.

are well dispersed with a relatively narrow size distribution and exhibit a single crystalline nature. The high-resolution TEM image also clearly reveals that the obtained $\mathrm{ZnO}$ nanopowders exhibited lattice fringes with an inter-planar distance of approximately $0.28 \mathrm{~nm}$, corresponding to the $(11 \overline{2} 0)$ plane of the hexagonal structure, as shown in Fig. 3(c). Fig. 3(d) is a schematic illustration showing that the lattice constant of the $\mathrm{ZnO}$ structure is very similar to that estimated by analysis of the HRTEM image.

Figure 4 depicts the UV-Vis spectra of the $\mathrm{ZnO}$ nanopowders synthesized by glycol process at various reaction temperatures. All of the samples exhibit reflectance thresholds of $382 \mathrm{~nm}$ and high reflectance in the visible range.

$$
(\mathrm{K} \times h v)^{2}=\left(h v-\mathrm{E}_{\mathrm{g}}\right), \mathrm{K}=\frac{(1-\mathrm{R})^{2}}{2 \mathrm{R}}
$$

Here, $K$ is the Kubelka-Munk absorption coefficient, $R$ is the reflectance (\%), and $h v$ is the photon energy. According to the plot of $[\mathrm{K} \cdot h v]^{2}$ versus energy, presented in Fig. 4 (inset), the band gap energy $\left(\mathrm{E}_{\mathrm{g}}\right.$ ) of the $\mathrm{ZnO}$ nanopowder

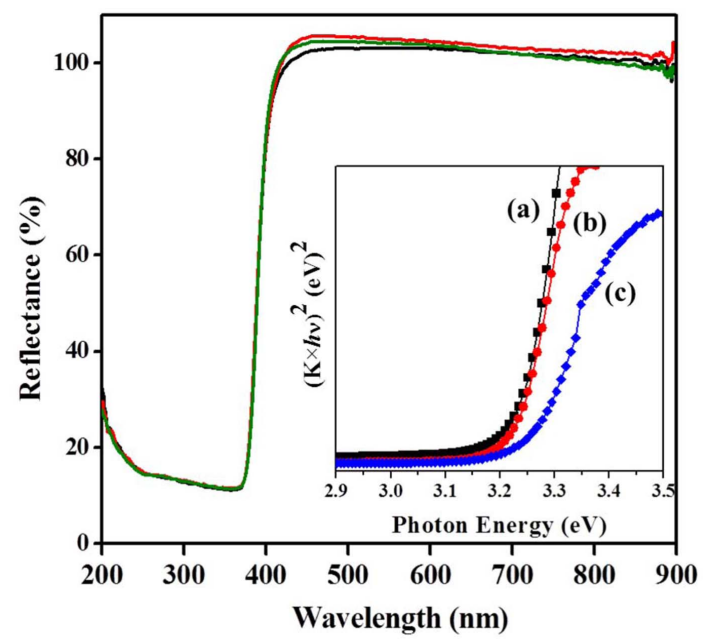

Fig. 4. UV-Vis DR spectra of $\mathrm{ZnO}$ nanopowder synthesized by glycol process at various reaction temperatures for $30 \mathrm{~min}$ and a plot of $(\mathrm{K} \times h v)^{2}$ vs. energy $(h v)$ of $\mathrm{ZnO}$ for band gap determination (inset): (a) $125^{\circ} \mathrm{C}$, (b) $150^{\circ} \mathrm{C}$, and (c) $175^{\circ} \mathrm{C}$. 


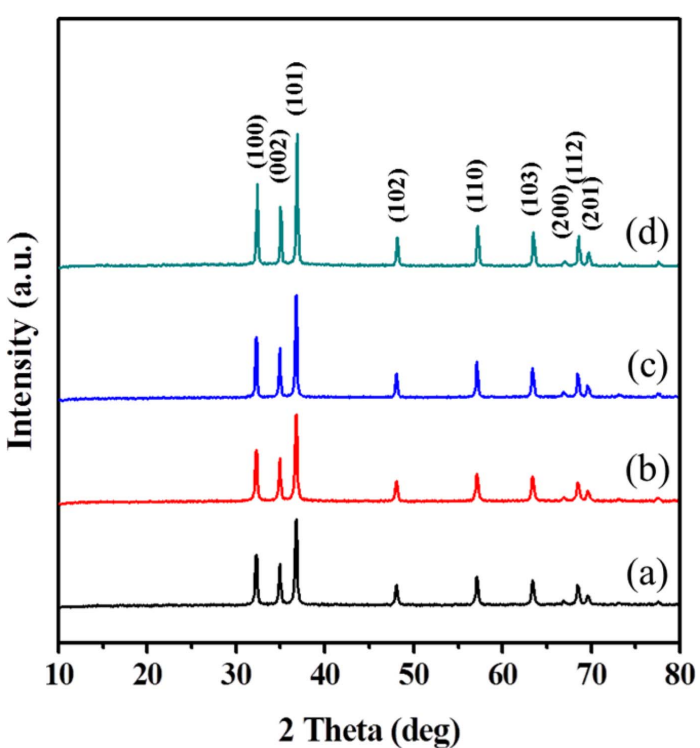

Fig. 5. XRD patterns of the $\mathrm{ZnO}$ powders synthesized by glycol process with various amounts of water at $150^{\circ} \mathrm{C}$ for $30 \mathrm{~min}$ : (a) $5 \mathrm{ml}$, (b) $10 \mathrm{ml}$, (c) $20 \mathrm{ml}$, and (d) $30 \mathrm{ml}$

was calculated and found to be $3.25 \mathrm{eV}$ by the extrapolation to $[\mathrm{K} \cdot h v]^{2}=0$. This result indicates that a $\mathrm{ZnO}$ nanopowder with a wide band gap energy was successfully synthesized.

The effect of water on the morphology of the $\mathrm{ZnO}$ powders under glycol reactions of binary solvent mixtures was investigated at $150^{\circ} \mathrm{C}$ for $30 \mathrm{~min}$. The XRD analysis results for the powders synthesized at different levels of water content (addition of 5 to $30 \mathrm{ml}$ ) are given in Fig. 5. Phase-pure $\mathrm{ZnO}$ powders with hexagonal structure were synthesized and improved with increasing water content.

Figure 6 shows the powder shape of $\mathrm{ZnO}$ synthesized under binary solvent at $150^{\circ} \mathrm{C}$ for $30 \mathrm{~min}$ when the water content increased from $5 \mathrm{ml}$ to $30 \mathrm{ml}$. The $\mathrm{ZnO}$ powders maintained a quasi-sphere shape without morphological change until the addition of $10 \mathrm{ml}$ of the water content. The size of these powders slightly increased from $40 \mathrm{~nm}$ to 50 $\mathrm{nm}$, as shown in Figs. 6(a) and (b). When $20 \mathrm{ml}$ of water was added, the morphology of the $\mathrm{ZnO}$ powders changed from quasi-spherical to hexagonal plate and pyramid, and the size increased to $100-200 \mathrm{~nm}$, as shown in Fig. 6(c). Furthermore, when water was added at a level of more than 30 $\mathrm{ml}$, the shape of the $\mathrm{ZnO}$ powder changed to hexagonal prismatic with pyramidal tip and the size of the powders increased drastically to approximately $200-500 \mathrm{~nm}$ in diameter and $0.5-1 \mathrm{\mu m}$ in length, as shown in Fig. 6(d). Based on the results, it is demonstrated that the size and morphology of $\mathrm{ZnO}$ powders can be controlled simply by changing the water content of the binary solvent mixture in the glycol process. The molecule of $\mathrm{Zn}\left(\mathrm{CH}_{3} \mathrm{COO}\right)_{2}$ is imperfectly soluble in 1,4-butanediol and is soluble in water. It is reasonable to assume that the solubility increased with increasing of the water content in the glycol condition of the mixed solvent. As the amount of water increase, more and more of the molecules of $\mathrm{Zn}\left(\mathrm{CH}_{3} \mathrm{COO}\right)_{2}$ dissolve in the 1,4-butanediol and water solution, which might lead to the fast growth of $\mathrm{ZnO}$ crystals and result in the formation of polyhedral $\mathrm{ZnO}$ hexagonal plates or pyramids and $\mathrm{ZnO}$ with a hexagonal prismatic shape and a pyramidal tip. ${ }^{17)}$

The mechanism of $\mathrm{ZnO}$ size control via the changing of
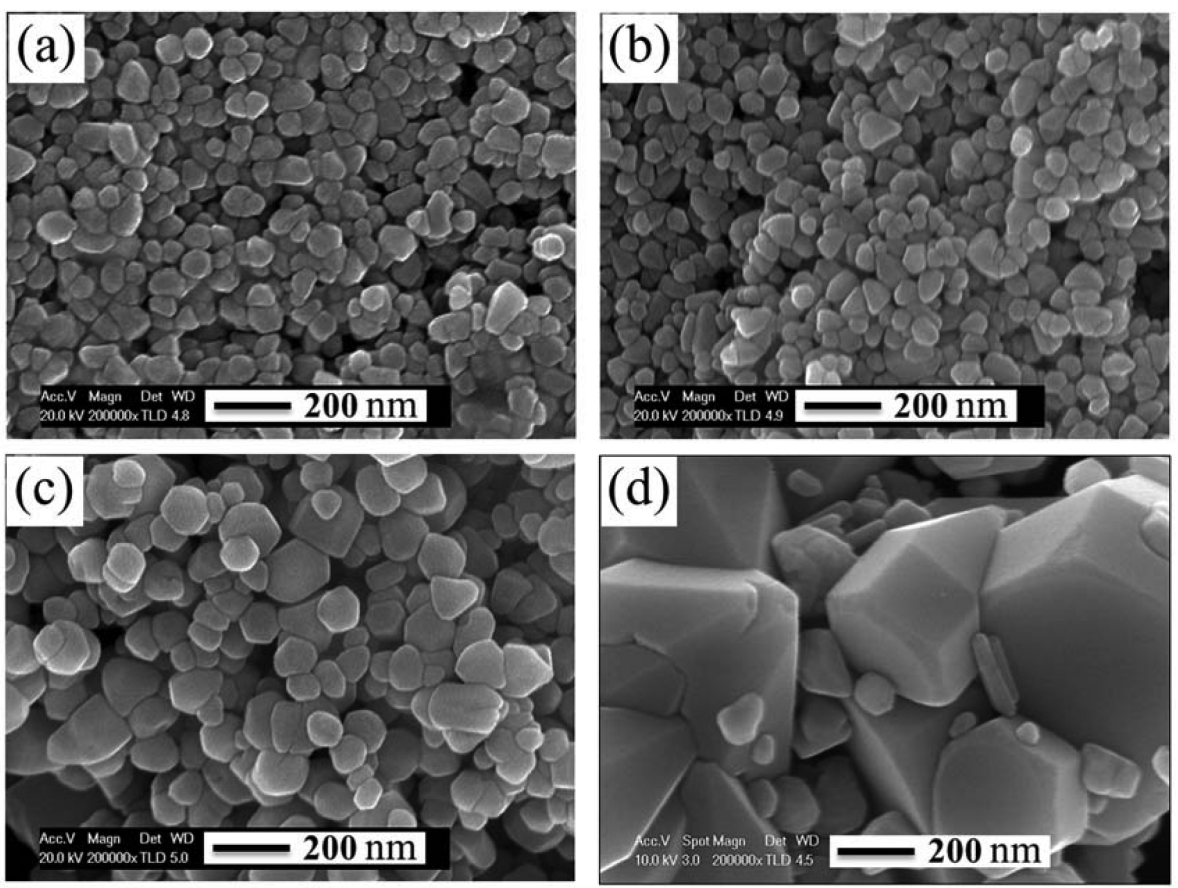

Fig. 6. FE-SEM images of the $\mathrm{ZnO}$ powders synthesized by glycol process with various amounts of water at $150^{\circ} \mathrm{C}$ for $30 \mathrm{~min}$ : (a) $5 \mathrm{ml}$, (b) $10 \mathrm{ml}$, (c) $20 \mathrm{ml}$, and (d) $30 \mathrm{ml}$. 

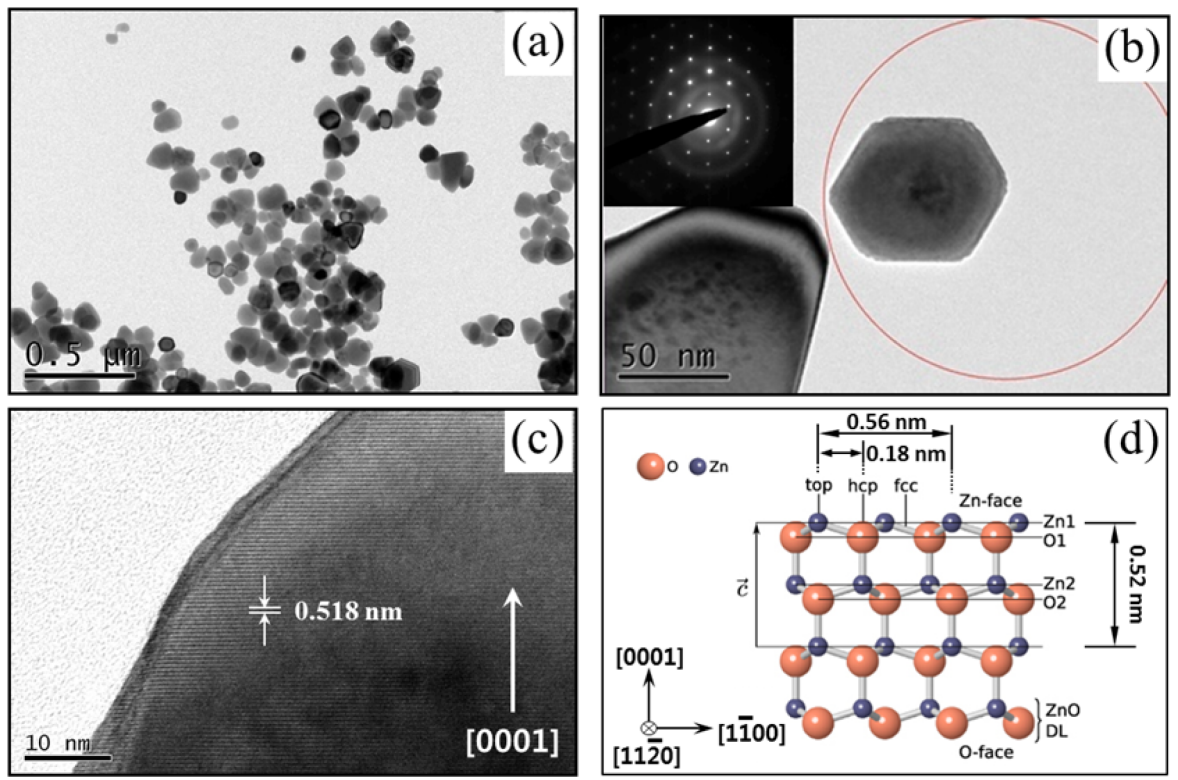

Fig. 7. (a) TEM image of the $\mathrm{ZnO}$ nanopowder obtained by glycol process with addition of $20 \mathrm{ml}$ of water as a binary solvent at $150^{\circ} \mathrm{C}$ for $30 \mathrm{~min}$; (b) SAED pattern, (c) HRTEM image, and (d) schematic illustration of side view of wurtzite structure and atom configuration.

the water content was the probably related to the impact of water on the simultaneous course of hydrolysis of $\mathrm{Zn}\left(\mathrm{CH}_{3} \mathrm{COO}\right)_{2}$, as well as being related to the generated intermediates. The $\mathrm{OH}^{-}$ion is supplied by the $\mathrm{CH}_{3} \mathrm{COO}^{-}$ion through hydrolysis. ${ }^{18)} \mathrm{Zn}$ and $\mathrm{O}$ atoms are stacked alternatively along the $c$-axis, and the top face (0001) consisting of tetrahedral zinc is terminated in $\mathrm{OH}^{-}$ligand due to addition of water. The formation of hexagonal pyramid- and prismlike $\mathrm{ZnO}$ crystals is attributed to the difference in the growth velocities of the various crystal facets. ${ }^{19)}$ The (0001) plane disappears due to its high growth velocity, leading to the pointed shape at the end of the $c$-axis. On the other hand, in the $\{10 \overline{1} 1\}$ planes and the $\{10 \overline{1} 0\}$ planes, due to slow growth velocity, the crystal remains to form hexagonal pyramid like tips and hexagonal prisms, respectively.

The TEM image and corresponding SAED pattern of the $\mathrm{ZnO}$ powders synthesized in glycol condition with $20 \mathrm{ml}$ of water at $150^{\circ} \mathrm{C}$ for $30 \mathrm{~min}$ are shown in Fig. 7. The $\mathrm{ZnO}$ powders with hexagonal plate and pyramid shape are well dispersed, have a relatively narrow size distribution, and exhibit a single crystalline nature. Fig. 7(b) shows the HRTEM image of the $\mathrm{ZnO}$ nanoplates. These are rather regular hexagon plates; the inset SAED pattern can be indexed as hexagonal $\mathrm{ZnO}$ along the [0001] axis; this also proves the single crystal structure. The HRTEM image shown in Fig. 7(c) clearly indicates that the $\mathrm{ZnO}$ lattice fringes, with an inter-planar distance of approximately $0.518 \mathrm{~nm}$, correspond to the $d$ spacing of (0001) planes, which reveals that the $c$-axis orientation is the potential growth direction.

PL spectra of the $\mathrm{ZnO}$ nanopowders synthesized by the glycol process were obtained using an He-Cd laser of 325 $\mathrm{nm}$ excitation at room temperature; the results are pre-

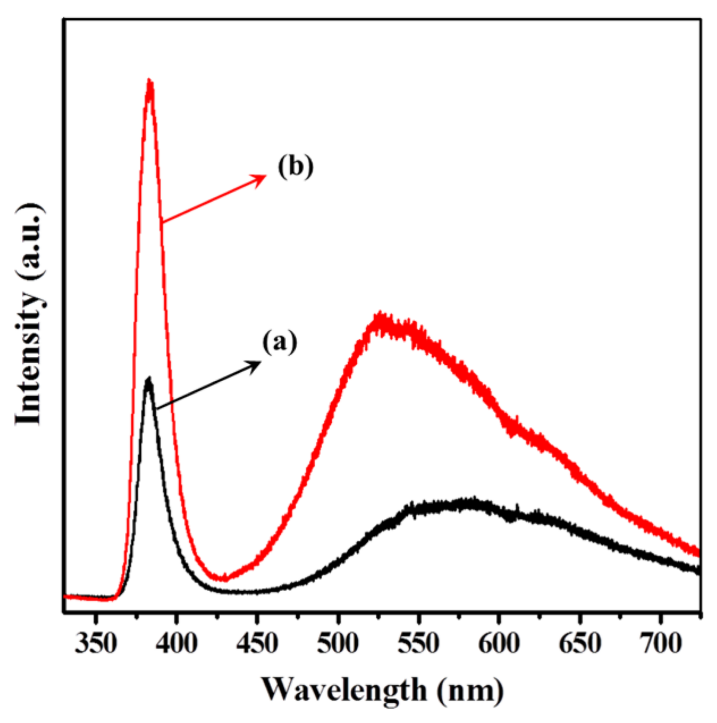

Fig. 8. PL spectra of the $\mathrm{ZnO}$ nanopowder synthesized by glycol process at $150^{\circ} \mathrm{C}$ for 30 min: (a) pure 1,4 butanediol solvent and (b) with addition of $20 \mathrm{ml}$ of water as a binary solvent.

sented in Fig. 8. It can be seen that there are two main emission peaks for both samples: the first are the strong PL peaks at approximately $384 \mathrm{~nm}$, which correspond to the typical $\mathrm{ZnO}$ near band edge UV emission with a band gap of $3.23 \mathrm{eV}$, and which are attributed to the recombination of free excitons. The others are wide band emissions extending from 450 to $700 \mathrm{~nm}$, related to the blue-yellow regions, and are attributed to the presence of ionized oxygen vacancies on the surface and to interstitial $\mathrm{Zn}$ ions..$^{20,21)}$ In our results, the strong UV emission should be attributed to the high 
purity with crystallinity of $\mathrm{ZnO}$ nanospheres.

\section{Conclusions}

In summary, $\mathrm{ZnO}$ nanopowders with hexagonal structures were successfully synthesized by glycol process at a temperature above $125^{\circ} \mathrm{C}$ for $30 \mathrm{~min}$. The quasi-spherical $\mathrm{ZnO}$ powder was found to have diameters of approximately 30 - $50 \mathrm{~nm}$ without morphological change when glycol was used as a solvent, regardless of the increase of the reaction temperature. With increasing water content, the shape of the $\mathrm{ZnO}$ powder changed dramatically from quasi-spherical to hexagonal plate and pyramid, and finally to hexagonal prismatic with a pyramidal tip. The size and morphology of $\mathrm{ZnO}$ can be successfully controlled by adjusting the water content of the binary solvent mixture via glycol process. In the PL measurements, all of the samples were found to exhibit a strong exciton-related UV emission with a weak defect peak, suggesting that the $\mathrm{ZnO}$ nanopowders achieve their best crystallinity and optical properties under these conditions.

\section{Acknowledgments}

This work was supported by the research grant of PaiChai University in 2016 (No. 2016A0136).

\section{REFERENCES}

1. A. Moezzi, A. M. McDonagh, and M. B. Cortie, "Zinc Oxide Particles: Synthesis, Properties and Applications," Chem. Eng. J., 185 1-22 (2012).

2. V. Kumar, N. Singh, V. Kumar, L. P. Purohit, A. Kapoor, O. M. Ntwaeaborwa, and H. C. Swart, "Doped Zinc Oxide Window Layers for Dye Sensitized Solar Cells," J. Appl. Phys., 114 [13] 134506 (2013).

3. Q. F. Zhou, C. Sharp, J. M. Cannata, K. K. Shung, G. H. Feng, and E. S. Kim, "Self-Focused High Frequency Ultrasonic Transducers based on ZnO Piezoelectric Films," Appl. Phys. Lett., 90 113502-3 (2007).

4. X. W. Li, P. Sun, T. L. Yang, J. Zhao, Z. Wang, W. Wang, Y. Liu, G. Lu, and Y. Du, "Template-Free Microwave-Assisted Synthesis of ZnO Hollow Microspheres and their Application in Gas Sensing," CrystEngComm, 15 [15] 2949-55 (2013).

5. U. Manzoor and D. K. Kim, "Synthesis and Enhancement of Ultraviolet Emission by Post-Thermal Treatment of Unique Zinc Oxide Comb-Shaped Dendritic Nanostructures," Scr. Mater., 54 [5] 807-11 (2006).

6. Ü. Özgür, D. Hofstetter, and H. Morkoç, "ZnO Devices and
Applications: A Review of Current Status and Future Prospects," Proc. IEEE, 98 [7] 1255-68 (2010).

7. J. Lee, A. J. Easteal, U. Pal, and D. Bhattacharyya, "Evolution of ZnO Nanostructures in Sol-Gel Synthesis," Curr. Appl. Phys., 9 [4] 792-96 (2009).

8. M. A. Mousa, W. A. A. Bayoumy, and M. Khairy, "Characterization and Photo-Chemical Applications of Nano-ZnO Prepared by Wet Chemical and Thermal Decomposition Methods," Mater. Res. Bull., 48 [11] 4576-82 (2013).

9. J. J. Wu and S. C. Liu, "Low-Temperature Growth of WellAligned ZnO Nanorods by Chemical Vapor Deposition," Adv. Mater., 14 [3] 215-18 (2002).

10. Y. H. Ni, X. W. Wei, J. M. Hong, and Y. Ye, "Hydrothermal Preparation and Optical Properties of ZnO Nanorods," Mater. Sci. Eng. B, 121 [1-2] 42-7 (2005).

11. Y. Fang, Z. Li, S. Xu, D. Han, and D. Lu, "Optical Properties and Photocatalytic Activities of Spherical $\mathrm{ZnO}$ and Flower-like ZnO Structures Synthesized by Facile Hydrothermal Method," J. Alloys Compd., 575 359-63 (2013).

12. J. Singh, S. S. Patil, M. A. More, D. S. Joag, R. S. Tiwari, and O. N. Srivastava, "Formation of Aligned ZnO Nanorods on Self-Grown ZnO Template and its Enhanced Field Emission Characteristics," Appl. Surf. Sci., 256 [21] 615763 (2010).

13. H. Zhang, R. Wu, Z. Chen, G. Liu, Z. Zhang, and Z. Jiao, "Self-Assembly Fabrication of 3D Flower-like ZnO Hierarchical Nanostructures and their Gas Sensing Properties," CrystEngComm, 14 [5] 1775-82 (2012).

14. T. Ipeksaç, F. Kaya, and C. Kaya, "Hydrothermal Synthesis of Zinc Oxide ( $\mathrm{ZnO})$ Nanotubes and its Electrophoretic Deposition on Nickel Filter," Mater. Lett., 100 11-4 (2013).

15. J. X. Wang, Y. Yang, and X. W. Sun, "ZnO Disk-like Structures and Their Application in Dye Sensitized Solar Cell," Solid State Commun., 240 46-52 (2016).

16. T. J. Hsueh, C. L. Hsu, S. J. Chang, and I. C. Chen, "Laterally Grown $\mathrm{ZnO}$ Nanowire Ethanol Gas Sensors," Sens. Actuator, B, 126 [2] 473-77 (2007).

17. J. Yin, F. Gao, C. Wei, and Q. Lu, "Water Amount Dependence on Morphologies and Properties of ZnO Nanostructures in Double-Solvent System," Sci. Rep., 43736 (2014).

18. H. Wang, C. Xie, and D. Zeng, "Controlled Growth of ZnO by Adding $\mathrm{H}_{2} \mathrm{O}$," J. Cryst. Growth, 277 [1] 372-77 (2005).

19. W.-J. Li, E.-W. Shi, W.-Z. Zhong, and Z.-W. Yin, "Growth Mechanism and Growth Habit of Oxide Crystals," J. Cryst. Growth, 203 [1] 186-96 (1999).

20. K. Vanheusden, W. L. Warren, C. H. Seager, D. R. Tallant, J. A. Voigt, and B. E. Gnade, "Mechanisms behind Green Photoluminescence in ZnO Phosphor Powders," J. Appl. Phys., 79 [10] 7983-90 (1996).

21. M. H. Huang, Y. Wu, H. Feick, N. Tran, E. Weber, and P. Yang, "Catalytic Growth of Zinc Oxide Nanowires by Vapor Transport,” Adv. Mater., 13 [2] 113-16 (2001). 